\title{
INFLUENCE OF GRAPE SEED EXTRACT SOLUTION ON MICROLEAKAGE BETWEEN COMPOSITE RESIN AND DENTIN
}

\section{SONNY PRASETYO WARDOJO, RATNA MEIDYAWATI*, MUNYATI USMAN}

\author{
Department of Conservative Dentistry, Faculty of Dentistry, Universitas Indonesia, Jakarta, Indonesia. Email: meidyawati58@gmail.com
}

Received: 21 April 2017, Revised and Accepted: 13 July 2017

\begin{abstract}
Objectives: The purpose of this study is to evaluate the influence of grape seed extract (GSE) solution as dentin biomodification on microleakage between composite resin and dentin.
\end{abstract}

Methods: A total of 52 dentin specimens were divided into two groups. Group 1 involved the application of GSE solution for 30 seconds after etching. Group 2 served as the control group.

Results: The GSE solution group significantly increases microleakage between the composite resin and dentin compared to the control group.

Conclusions: The application of GSE solution after etching can increase microleakage between composite resin and dentin.

Keywords: Microleakage, Dentin, Composite, Grape seed extract solution.

(C) 2017 The Authors. Published by Innovare Academic Sciences Pvt Ltd. This is an open access article under the CC BY license (http://creativecommons. org/licenses/by/4. 0/) DOI: http://dx.doi.org/10.22159/ijap.2017.v9s1.09_10

\section{INTRODUCTION}

Composite resin filling is a material that is often used for dental fillings, especially on the anterior teeth. Composite resin has a varied selection of colors that can resemble the color of teeth and requires minimal preparation $[1,2]$. Composite resin is one type of adhesive restoration, which is needed to attach the restoration to enamel and dentin. Buonocore discovered the first generation of adhesive systems in 1955, and since then, eight generations have been developed [3]. Dentin in humans consists of 50\% inorganic material, $25 \%$ organic material, and $25 \%$ water. Most inorganic material in dentin is composed of hydroxyapatite. Meanwhile, $90 \%$ of the composition of organic material consists of collagen fibers Type I, and the rest is noncollagen protein [3]. The parts of dentin that play a role in the process of adhesion are dentinal tubules and intertubular dentin. Etching the dentinal tubules is done to dispose of the smear layer that formed during the process of mechanical teeth preparation. If the dentinal tubules are opened, this can allow the bonding material to penetrate the dentinal tubules, forming resin tags. Meanwhile, in the intertubular area, some minerals will dissolve as deep as $6 \mu \mathrm{m}$ due to etching for 15 seconds, leaving collagen fibers for the adhesive attachment. The bonding material will penetrate the gap of the collagen fibers forming the hybrid layer. The bonding of composite resins to dentin is harder than their bonding to enamel due to the heterogeneous characteristics of dentin, which increase the possibility of adhesive failure [3-5].

The failure of the adhesive in a composite resin filling occurs due to several factors, including the smear layer covering the dentinal tubule layer, the permeability of dentinal tubule fluid, the contraction force between the composite resin and teeth during the polymerization process, and damage to the hybrid layer. The failure of the adhesive results in microleakage between composite resin fillings in teeth. Microleakage is a gap between the filling and a tooth, which permits the entry of fluid or bacteria into the gap. Bacteria and liquid that penetrate the microcracks can lead to secondary caries, hypersensitivity, and irritation of the pulp [3]. Microleakage in the teeth most often occurs in the gingival wall. The gingival wall is formed by dentin; dentin consists of minerals, organic components, and dentinal tubules, which contain fluid that complicates the process of adhesion [6]. Grape seed extract (GSE) contains Vitamin E, flavonoids, linoleic acid, and proanthocyanidin. Recently, in the world of dentistry, there have been new developments regarding the beneficial effects of GSE. Some of the properties of GSE that have been examined make it possible for GSE to be used as a root canal irrigation material, antibacterial against Enterococcus faecalis and Streptococcus mutans, and a dentin collagen cross-linking booster [7-10]. GSE can be obtained by directly extracting grape seed or using GSE that has been mass produced. Today, many GSE solutions are sold in packaging for use as health supplements.

The previous study reported that the use of GSE can strengthen collagen cross-linking so that the condition of the collagen fibers can be stable and more resistant to damage [11]. Liu et al. conducted a study of dentin specimens that were etched for 15 seconds, then dentin mineral becomes soluble so that $6 \mu \mathrm{m}$ of the collagen was exposed, collagen that is exposed will be more susceptible to damage when contaminated with the collagenase enzyme derived from bacteria and saliva [10]. In this study, GSE with $0.5-15 \%$ proanthocyanidin was applied to the specimens, and then the specimens were immersed in a solution containing the enzyme collagenase. Spectroscopic observations showed that the application of GSE with 2-15\% proanthocyanidin for 30 seconds can prevent further damage to collagen. Thus, GSE with $2-15 \%$ proanthocyanidin can be used as a dentin biomodification ingredient to prevent collagen damage that can lead to microleakage. This study will compare microleakage between a composite resin filling and dentin using a total-etch bonding system with the application of GSE solution on dentin.

\section{METHODS}

The specimens used included 52 layers of dentin derived from maxillary premolar teeth removed for orthodontic purposes. Before the teeth were used, they were stored in saline water and used within 1 month after extraction. Teeth that were used had to meet the inclusion and exclusion criteria. Enamel on the mesial and distal premolars was removed using a diamond bur, leaving only the dentin tissue. The research sample was then divided into two treatment groups, respectively, with a total of 26 samples. Group 1 was treated as follow: Dentin was etched with $37 \%$ phosphoric acid for 15 seconds, rinsed 
with running water for 5 seconds, and sprayed with light wind. GSE solution was then applied to the dentin for 30 seconds, and then rinsed with water. In humid conditions, the dentin was bonded for 15 seconds, then sprayed with light wind for 5 seconds, and then irradiated for 15 seconds (according to the rules of the factory). Group 2 (control group) was treated as follow: Dentin was etched with $37 \%$ phosphoric acid for 15 seconds, rinsed with running water for 5 seconds, and sprayed with light wind. In humid conditions, the dentin was bonded for 15 seconds, then sprayed with light wind for 5 seconds, and then irradiated for 15 seconds (according to the rules of the factory).

In both groups, composite resin filling procedures were performed using a mold round with a $6-\mathrm{mm}$ diameter and $1-\mathrm{mm}$ height. The composite was then irradiated for 20 seconds. The entire surface of a tooth receiving a filling was covered by nail polish up to $1 \mathrm{~mm}$ from the edge of the restoration. The specimen was then soaked with a solution of $1 \%$ blue methylene for $24 \mathrm{hrs}$ at room temperature. Next, the specimen was dried, left for $24 \mathrm{hrs}$, and rinsed with running water. Samples were split using a diamond disc in a horizontal direction without water at the mid-restoration point horizontally. The penetration of blue methylene was checked for each piece using a microscope with a 20 -times magnification and a millimeter grid. The biggest leakage rate on each side was used as the data. If the data were normally distributed, the data obtained from each group were analyzed using an independent t-test. However, if the data distribution was not normal, then the analysis was completed using the Mann-Whitney test.

\section{RESULTS}

This study analyzed the influence of GSE solution on the amount of microleakage between a composite resin filling and dentin. Observations were made with a stereomicroscope with a magnification of 20 times. The depth of the penetration of blue methylene that showed microleakage was measured in millimeters using a millimeter grid. On the normality test, data were obtained for samples $>50$; then, the Kolmogorov-Smirnov test was used, and the obtained value was $\mathrm{p}<0.05$. It could be concluded from the distribution of data in both groups that the data were not normal. Therefore, an analysis of the data was completed, followed by the use of the non-parametric Mann-Whitney test. On the Mann-Whitney test, a value of $\mathrm{p}<0.05$ was obtained, so it can be concluded that there was a significant difference in microleakage between the groups that applied GSE after etching and control.

In Table 1, the median and mean scores for microleakage between a composite resin filling and dentin in the GSE group after etching is higher than that of the control group. The significance value of both groups is $\mathrm{p}=0.001$, and because $\mathrm{p}<0.05$, it can be concluded that there was a significant difference in microleakage between the groups that applied GSE after etching and control. In Table 2, the smallest percentage of microleakage between resin composite filling and dentin $(0 \%)$ is in the group of $0 \mathrm{~mm}$ of GSE solution microleakage, and the greatest percentage $(73 \%)$ is in the control group with no microleakage.

\section{DISCUSSION}

This study analyzed the effect of GSE solution on microleakage between a composite resin filling and dentin in vitro. The background of this research refers to the research of Liu and Wang, which highlighted the ability of GSE as a reinforcement material for dentin collagen crosslinking after etching, to prevent damage to collagen fibers that can lead to microleakage [9]. Dentin specimens were taken from the first and second maxillary premolars that were removed for orthodontic purposes, by removing the enamel surface in mesial and distal sections. The selection of the samples of the extracted teeth was done with the aim of achieving uniformity in the samples so that any anatomical variations that could be found among the samples were minimal. The teeth were soaked in saline water and used within 1 month after their extraction to keep them in moist conditions, especially the collagen in the dentin [11].
Table 1: Mean $\pm S D$ and $\mathrm{CI}$ of microleakage between composite resin and dentin in GSE and control groups

\begin{tabular}{lclll}
\hline $\begin{array}{l}\text { Treatment } \\
\text { group }\end{array}$ & $\mathbf{n}$ & $\begin{array}{l}\text { Median (mm) } \\
\text { (minimum-maximum) }\end{array}$ & Mean \pm SD & p value \\
\hline $\begin{array}{l}\text { GSE } \\
\text { solution }\end{array}$ & 26 & $2(1-3)$ & $1.8 \pm 0.75$ & 0.001 \\
Control & 26 & $1(0-2)$ & $1.2 \pm 0.52$ & \\
\hline
\end{tabular}

Mann-Whitney statistic test, significant value of $p<0.05$. SD: Standard deviation, GSE: Grape seed extract, CI: Confidence interval

Table 2: Summary and percentage of microleakage between composite resin and dentin in GSE and control groups

\begin{tabular}{lll}
\hline Microleakage (mm) & GSE solution (\%) & Control (\%) \\
\hline 0 & 0 sample (0) & 2 samples (7) \\
1 & 10 samples (38) & 19 samples (73) \\
2 & 11 samples (42) & 5 samples (19) \\
3 & 5 samples (19) & 0 samples (0) \\
\hline GSE: Grape seed extract &
\end{tabular}

To achieve adhesion between the composite resin and dentin, an adhesive system was needed. The adhesive system used in this study is the fifth-generation total-etch, where etching is done in the enamel and dentinal areas, followed by the application of a monomer bonding material. Etching on dentin is done to dispose of the smear layer that closes the dentinal tubules so that the bonding material can penetrate the dentinal tubules forming resin tags. Meanwhile, on intertubular dentin, etching will cause the demineralization of most mineral layers and leave only collagen fibers. The bonding material then penetrates the gap of the collagen fibers forming the hybrid layer. The dry conditions of the dentin will result in the collapse of the collagen fibers and complicate the penetration of the bonding material [3]. Based on research that Malik et al. conducted in 2014, the moist conditions of the dentin will cause the collagen fibers to stand up and will facilitate the penetration of the bonding material into the gap of the collagen fibers. The bonding material, which is hydrophilic, will replace the existing water in the collagen fibers. The remaining water will then be wasted during the process of flattening the bonding material using sprayed wind [12].

The composite used in this study was nanotype. Nanocomposites have filler particles that are $0.1-100 \mathrm{~nm}$ in size; this type of composite has greater esthetic properties and strength compared with microfill and hybrid composite resin. Since it is so good, it is often used as a nanocomposite filling in the anterior and posterior teeth [13]. The composite filling in this study lay on one field surface, that is, the pulp wall with the lowest C-factor and minimized the occurrence of composite shrinkage when polymerization occurred, which can lead to microleakage. When the polymerization of monomer material in the composite resin is transformed into polymers, shrinkage occurs and potentially causes microleakage $[3,14]$. This study was performed in vitro with dye penetration methods that Taylor and Lynch introduced in 1992. This method can reveal microleakage through the penetration of dye between composite resin fillings and teeth. The dye used in this study is blue methylene $1 \%$. This substance has very small particles $(<2 \mu \mathrm{m})$ compared with India ink $(10 \mu \mathrm{m})$, even smaller than dentinal tubules $(1-4 \mu \mathrm{m})$, and bacteria $(2-4 \mu \mathrm{m})$, which helps to explain the microleakage that occurs in composite resin fillings and teeth $[15,16]$. To prevent the penetration of blue methylene into open dentinal tubules, the entire surface of a tooth is covered by nail polish up to $1 \mathrm{~mm}$ from the edge of the composite filling.

The GSE solution used in this study contained 2.9\% proanthocyanidin. Proanthocyanidin has the ability to be a collagen cross-linking booster. Proanthocyanidin consists of a free hydroxyl phenyl group that has the ability to bind a protein amino acid. The phenyl hydroxyl group forms 
new hydrogen bonds that are more stable with the hydroxyl, carboxyl, amino, and amide chain groups. According to Liu et al., the application of GSE with 2-15\% proanthocyanidin for 30 seconds on dentin that has been etched can improve cross-linking between collagen fibers, making the collagen fibers more resistant to damage that can lead to microleakage [10,17-19]. Therefore, in this study, the application of GSE solution for 30 seconds was sufficient for increasing the cross-linking of collagen dentin, according to research by Liu and Wang [9].

The results showed that the median value of the microleakage of the GSE solution application group after etching was greater than that of the control group, and there was statistically no significant difference between the two $(\mathrm{p}=0.001)$. This means that microleakage improved in the GSE solution application group. Thus, the hypothesis that GSE solution application can reduce the value of microleakage between dentin and a composite resin filling was rejected. Microleakage in the GSE solution application group was mostly $2 \mathrm{~mm}(42 \%)$, followed by a leakage of $1 \mathrm{~mm}(38 \%)$ and a leakage of $3 \mathrm{~mm}(19 \%)$. It was larger than that of the control group, which had the highest leakage of $1 \mathrm{~mm}$ (73\%). Microleakage on dentin cannot be eliminated entirely due to the condition of dentin, which contains many organic tissues. It is different from the enamel, of which $90 \%$ consists of an inorganic network. Some research on microleakage indicated that it can still happen between a composite resin filling and dentin; therefore, microleakage at a scale of $1 \mathrm{~mm}$ is still considered tolerable. Clinically, microleakage on dentin is still protected by the density between the enamel and resin composites $[3,6,11]$. The amount of microleakage in the GSE solution application group after etching was possibly the result of the presence of other substances in the GSE solution used in this study. The GSE solution that was used is a type of mass-produced beverage. The composition of this solution includes water, GSE, and glycerin.

Glycerin has the chemical formula of $\mathrm{C}_{3} \mathrm{H}_{5}(\mathrm{OH})_{3}$. Hydrogen bonds are formed with water, so glycerin can be dissolved in water or alcohol. Glycerin has the properties of being colorless, odorless, hydrophilic, hygroscopic, and a certain viscosity. Glycerin is obtained from a byproduct of saponification or from the process of making soap from animals and vegetables. The content of glycerin in GSE solution functions as a thickening agent. If GSE solution is applied to dentin that is etched for 30 seconds and then rinsed with water spray for 15 seconds, this will likely still leave a residue. Glycerin has a high viscosity and can be dissolved only by water, followed by mechanical cleaning. Residual glycerin is expected to remain attached to the collagen fibers and is not dissolved by water rinses. This causes delays in bonding in the demineralized dentin layer, thereby disrupting the formation of the hybrid layer and increasing the occurrence of microleakage [20]. Based on a scanning electron microscope examination of the GSE solution application group, there seems to be a gap in the hybrid layer. Gaps are likely due to the carryover of glycerin on collagen fibers, thereby disrupting the penetration of bonding and causing the hybrid layer not to form perfectly. The fact that GSE and glycerin may not be washed away by water spray could potentially interfere with the polymerization process of composite. Proanthocyanidin in GSE is known to have free radical compounds that can interfere with the process of composite resin polymerization [21].

\section{CONCLUSION}

The application of GSE solution for 30 seconds after etching has increased the likelihood of microleakage between a composite resin filling and dentin. Further research needs to be done with the same method concerning microleakage between composite resin fillings and dentin using pure GSE.

\section{REFERENCES}

1. Wirsching E. Contemporary options for restoration of anterior teeth with composite. Quintessence Int 2015;46(6):457-63.

2. Staehle HJ, Wolff D, Frese C. More conservative dentistry: Clinical long-term results of direct composite resin restorations. Quintessence Int 2015;46(5):373-80.

3. Predigao J, Swift E. Fundamental concepts of enamel and dentin adhesion. In: Roberson M, Heymann H, Swift E, editors. Studervant's Art and Science Operative Dentistry. $5^{\text {th }}$ ed. St. Louis: Mosby Elsevier; 2002. p. 239-61.

4. Perdigão J, Reis A, Loguercio AD. Dentin adhesion and MMPs: A comprehensive review. J Esthet Restor Dent 2013;25(4):219-41.

5. Mazzoni A, Tjäderhane L, Checchi V, Di Lenarda R, Salo T, Tay FR, et al. Role of dentin MMPs in caries progression and bond stability. J Dent Res 2015;94(2):241-51.

6. Rosales-Leal JI. Microleakage of Class V composite restorations placed with etch-and-rinse and self-etching adhesives before and after thermocycling. J Adhes Dent 2007;9 Suppl 2:255-9.

7. Angelina A. Potensi Ekstrak Biji Anggur Sebagai Larutan Irigasi Saluran Akar Dalam Membersihkan Smear layer (Tesis). Jakarta: Universitas Indonesia; 2013.

8. University of Maryland Medical Center (UMMC). APGAR; 2011. Available from: http://www.umm.edu/health/medical/spanishpreg/ trabajo-de-parto-y-parto/indice-de-apgar.

9. Liu Y, Wang Y. Proanthocyanidins' efficacy in stabilizing dentin collagen against enzymatic degradation: MALDI-TOF and FTIR analyses. J Dent 2013;41(6):535-42.

10. Liu Y, Dusevich V, Wang Y. Addition of grape seed extract renders phosphoric acid a collagen-stabilizing etchant. J Dent Res 2014;93(8):821-7.

11. Singla M, Aggarwal V, Kumar N. Effect of chlorhexidine cavity disinfection on microleakage in cavities restored with composite using a self-etching single bottle adhesive. J Conserv Dent 2011;14(4):374-7.

12. Malik S, Bal C, Singh R. Tensile bond strength of total-etch and selfetch adhesives on moist and dry dentin in-vivo study. Indian J Compr Dent Care 2014;4:422-7.

13. Reddy S. Nano composites-synthesis, characterization and industrial applications. Alex Eng J 2014;6:14-6.

14. Swapna MU, Koshy S, Kumar A, Nanjappa N, Benjamin S, Nainan MT. Comparing marginal microleakage of three Bulk Fill composites in Class II cavities using confocal microscope: An in vitro study. J Conserv Dent 2015;18(5):409-13.

15. Nguyen C. A new in vitro method for study of microleakage of dental restorative material. University of Adelaide Australia; 2013. p. 15-18.

16. Ahlberg KM, Assavanop P, Tay WM. A comparison of the apical dye penetration patterns shown by methylene blue and india ink in rootfilled teeth. Int Endod J 1995;28(1):30-4.

17. Kalra M, Iqbal K, Nitisusanta LI, Daood U, Sum CP, Fawzy AS. The effect of proanthocyanidins on the bond strength and durability of resin sealer to root dentine. Int Endod J 2013;46(2):169-78.

18. Kaur R, Bak C, Khanna R, Bhullar K, Malhotra S. Effect of pretreatment with grape seed extract on the bond strength of self etch adhesive. Indian J Compr Dent Care 2014;4:15-8.

19. Green B, Yao X, Ganguly A, Xu C, Dusevich V, Walker MP, et al. Grape seed proanthocyanidins increase collagen biodegradation resistance in the dentin/adhesive interface when included in an adhesive. J Dent 2010;38(11):908-15.

20. da Silva NR, Calamia CS, Coelho PG, Carrilho MR, de Carvalho RM, Caufield $\mathrm{P}$, et al. Effect of $2 \%$ iodine disinfecting solution on bond strength to dentin. J Appl Oral Sci 2006;14(6):399-404.

21. Liu Y, Wang Y. Effect of proanthocyanidins and photo-initiators on photo-polymerization of a dental adhesive. J Dent 2013;41(1):71-9. 